\title{
Simulation Analysis of Policy for Waste Treatment toward a Sound Material-cycle Society in Tokyo
}

\author{
Noriko Nozaki ${ }^{1}$, Keyu $\mathrm{Lu}^{2}$, Rajeev Kumar Singh ${ }^{3}$, Takeshi Mizunoya ${ }^{4}$, Helmut Yabar ${ }^{4} \&$ Yoshiro Higano ${ }^{4}$ \\ ${ }^{1}$ Graduate School of Life and Environmental Sciences, University of Tsukuba, Tsukuba, Ibaraki, Japan \\ ${ }^{2}$ Science \& Research Department, Chinese Society for Urban Studies, Beijing, China \\ ${ }^{3}$ Sustainable Consumption and Production (SCP), Institute for Global Environmental Strategies (IGES), Hayama, \\ Kanagawa, Japan \\ ${ }^{4}$ Faculty of Life and Environmental Sciences, University of Tsukuba, Tsukuba, Ibaraki, Japan \\ Correspondence: Noriko Nozaki, Graduate School of Life and Environmental Sciences, University of Tsukuba, \\ 1-1-1 Tennodai, Tsukuba, Ibaraki 305-8572, Japan. Tel: 81-29-853-7255. E-mail: nrknzk.621@gmail.com
}

Received: May 16, 2017

doi:10.5539/jsd.v10n4p65
Accepted: July 12, $2017 \quad$ Online Published: July 30, 2017

URL: https://doi.org/10.5539/jsd.v10n4p65

\begin{abstract}
Enhancing resource productivity is effective to improve trade-off between the environment and economy. For minimizing consumption of natural resources required for economic activities, it is necessary to strengthen both material recycling and energy utilization, which reduce final disposal amount and return waste to economic activities as resource.

This study seeks to clarify environmental economic policy for promoting establishment of sound material-cycle society subject to keeping or expanding the regional economic scale, and enhancing the amount of material recycling and reducing greenhouse gas (GHG) emissions. Study area is Tokyo metropolitan area. To reduce GHG emissions and final disposal amount, we consider promoting both material recycling and energy utilization thoroughly. Under these circumstances, we construct an expanded input-output model. The model includes the flows of waste and energy, and emissions of GHG. With restrictions on GHG emissions, Gross Regional Product (GRP) is maximized as the objective function. We quantitatively analyze how much tax and subsidy on discharging waste is required for sound material-cycle society along with analysis on effects of the policy by model simulation.

The results show that, with 10 yen/kg tax on discharging waste, final disposal amount per GRP was $11 \%$ lower than the baseline case.
\end{abstract}

Keywords: energy utilization, input-output model, material recycling, policy evaluation, waste

\section{Introduction}

In the 1960s, during so-called high-growth period, economic activities in Japan were based on mass-production, mass-consumption and mass-disposal. This social structure initiated many environmental issues such as depletion of natural resources, shortage of landfill site and excessive emission of pollutants including GHG along with outbreak of four major environmental pollutions in Japanese history. The fundamental problem with this society is existence of trade-off between the environment and economic growth. To improve the trade-off and shift the society with a sustainable economic system, it is effective to enhance resource productivity with the idea of a sound material-cycle society.

In Japan, legal systems to establish a sound material-cycle society has already implemented around 2000 (Bureau of Environment, 2014). However, in Tokyo, majority of waste is simply incinerated and the ash goes to landfill site (Bureau of Environment, 2014). When we consider only biomass in waste, potential energy corresponds to $14.1 \%$ of the energy consumption in Tokyo whereas the actual use in 2011 is only about $5.2 \%$ of the potential energy per our estimation (see Figure 1 and Table 1). Moreover, biomass is mostly used for generating power through incineration. There are more efficient methods for biomass such as methane fermentation and conversion into biodiesel fuel (BDF). If we use these methods, we can achieve higher resource productivity. 


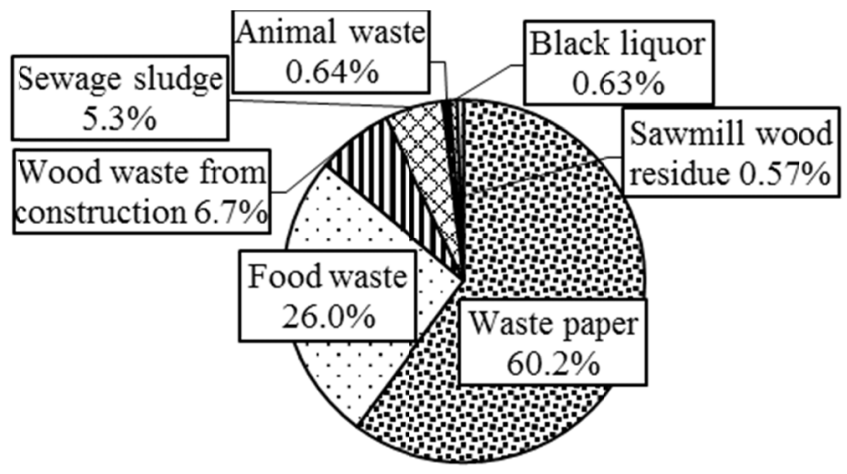

Figure 1. Composition of biomass generated in Tokyo in 2010

Table 1. Potential of utilizing biomass to energy and current situation in Tokyo in 2010

\begin{tabular}{lcc}
\hline \multicolumn{1}{c}{ Type of biomass } & $\begin{array}{c}\text { Potential of biomass } \\
\text { to energy (TJ) }\end{array}$ & $\begin{array}{c}\text { Methods used for biomass to energy and its } \\
\text { conversion amount (TJ) }\end{array}$ \\
\hline Animal waste & 297.5 \\
Sewage sludge & 3593.3 Carbonization 72, Methane fermentation 84 \\
Black liquor & 635.7 \\
Waste paper & 41626.9 \\
Food waste & 38696.3 Methane fermentation 28, Conversion into BDF 418 \\
Sawmill wood residue & 779.0 \\
Wood waste from construction & 9302.0 \\
Total & 94930.73067 (Including waste power generation 2465) \\
\hline
\end{tabular}

Besides, after the Great East Japan Earthquake in 2011, GHG emissions per amount of energy consumption is getting higher. Figure 2 shows changes in GHG emissions and energy consumption in Tokyo (Bureau of environment, 2015). The trends show opposite directions since 2011. Tokyo Metropolitan Government has set a GHG reduction target to reduce Tokyo's GHG emissions by 25\% below 2000 levels by 2020 (Bureau of environment, 2015). According to the latest data published by bureau of environment, the GHG emissions amount was 70.1 million $\mathrm{t}-\mathrm{CO}_{2}$ eq in 2013 (Bureau of environment, 2015). This data reveals that we need to reduce $33.9 \%$ from 2013 level to meet the target. It is necessary to reconsider types of energy and change into low GHG emissions technologies to fulfill GHG reduction target.

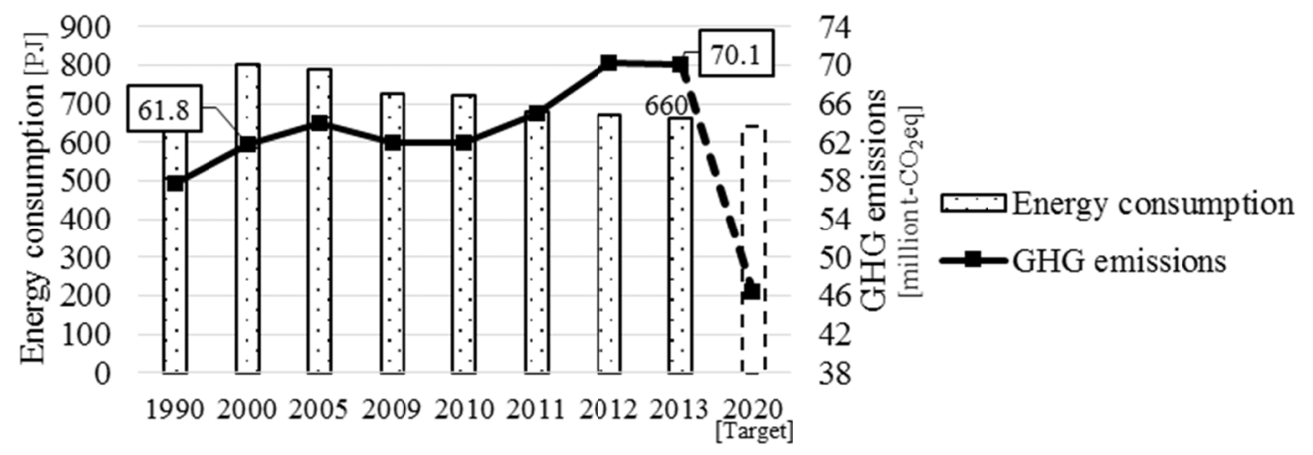

Figure 2. GHG emissions and energy consumption in Tokyo

There are numbers of research related to environmental economic policy. Iwata and Shimada (2008) constructed a model to quantify various effect of livestock manure and discussed cost-effectiveness. Chang and Lin (1998) conducted input-output structural decomposition analysis to examine industrial $\mathrm{CO}_{2}$ emission structure. Higano 
(1996) discussed distribution of value added to environmental goods focusing on value added tax derived by using the linear ecosystem model which considers value flow and material flow. Using model based on material balance, Uchida and Higano (2006) and Mitsuhashi and Higano (2005) analyzed environmental and economic effects of introducing energy utilization from waste biomass as an industrial sector. $\mathrm{Li}$, Zou, $\mathrm{Xu}$, Yabar, and Higano (2012) focused on E-waste and found the optimal allocation of cost between producers and consumers of electronic products by minimizing $\mathrm{CO}_{2}$ emission.

Although some research have been done on either material recycling or energy utilization, there are very few research considering both. However, with recycling more waste thorough using various ways, we can bring waste back as resource for economic activities and reduce final disposal amount. From this point of view, we consider promoting both material recycling and energy utilization, and clarify optimal situation for waste recycling system in this study. The purpose of this study is to clarify environmental economic policy for promoting establishment of sound material-cycle society with economic and environmental preconditions, namely keeping or expanding the regional economic scale and reducing GHG emissions amount.

\section{Method of Study}

This study constructs a socioeconomic model based on interregional input-output table which includes import and export from both other regions in Japan and abroad. We set two new waste treatment sectors consist of material recycling and energy utilization as new industries. The model includes flows of waste and energy, and emission of GHG. We expand this model into linear programming problem, and conduct computer simulation analysis. Activities of new industries are motivated by subsidy from tax levied on amount of waste discharged from both industries and households. With restriction on emissions of GHG, GRP is maximized as the objective function. Making the emission standards strict step by step, we quantitatively analyze how much tax and subsidy on discharging waste is required for sound material-cycle society thoroughly.

The model consists of three economic agents: industry, households and the government, as shown in Figure 3 and Figure 4. Industry sector consists of 9 industries, and each industries are subdivided into smaller sections. We set 97 sections in total, which are Usual industries in Tokyo with 24 sections and in other region with 28 sections, Energy industries in Tokyo and in other region with 12 sections respectively, Waste treatment industries in Tokyo and in other region with 2 sections respectively, New waste treatment industries in Tokyo (material recycling) with 4 sections, New waste treatment industries in Tokyo (energy utilization) with 9 sections, and Material recycled goods utilizing industries in Tokyo with 4 sections. Material recycled by New waste treatment industries in Tokyo (material recycling) goes to Material recycled goods utilizing industries. Therefore these industries have same sections, which are glass, paper, plastics and metal section. The model is applied to Japanese economy as of 2011. We consider 6 types of GHG, namely $\mathrm{CO}_{2}, \mathrm{CH}_{4}, \mathrm{~N}_{2} \mathrm{O}, \mathrm{HFCs}$, PFCs and $\mathrm{SF}_{6}$.

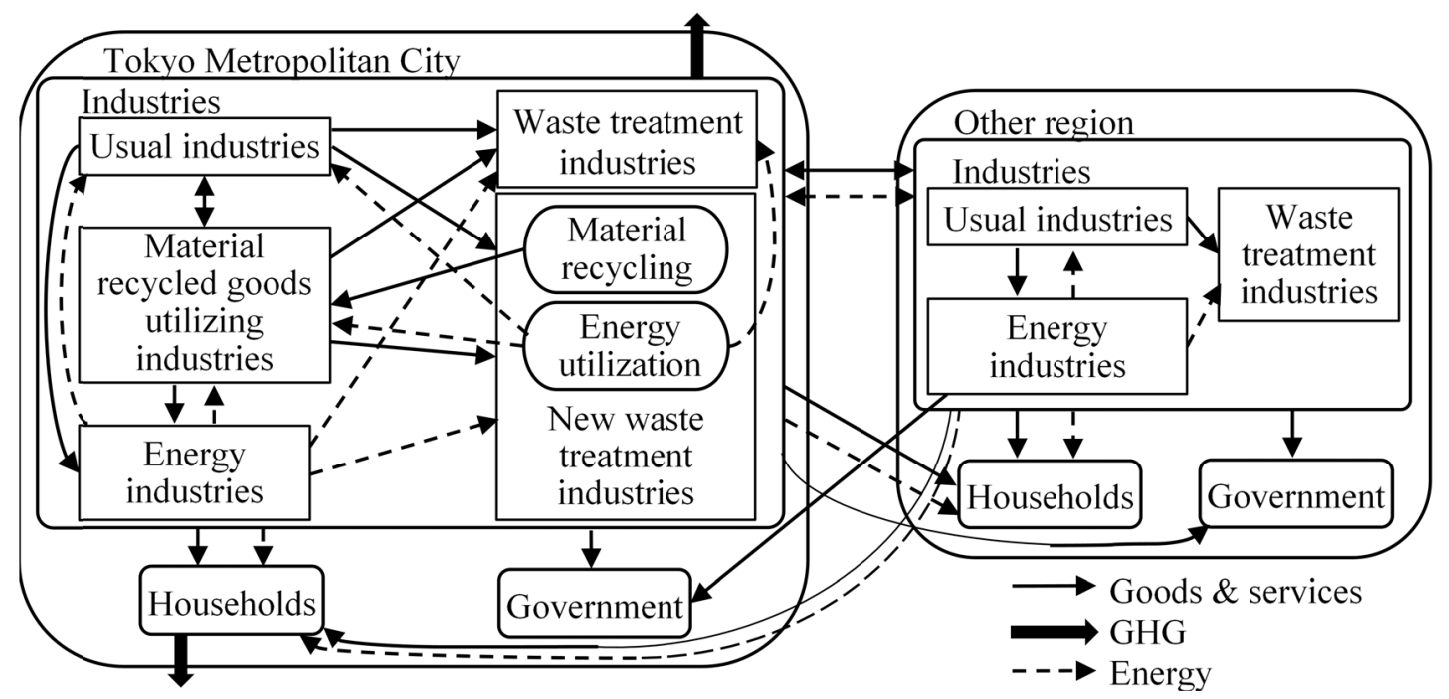

Figure 3. Flow chart of goods \& services, GHG, and energy 

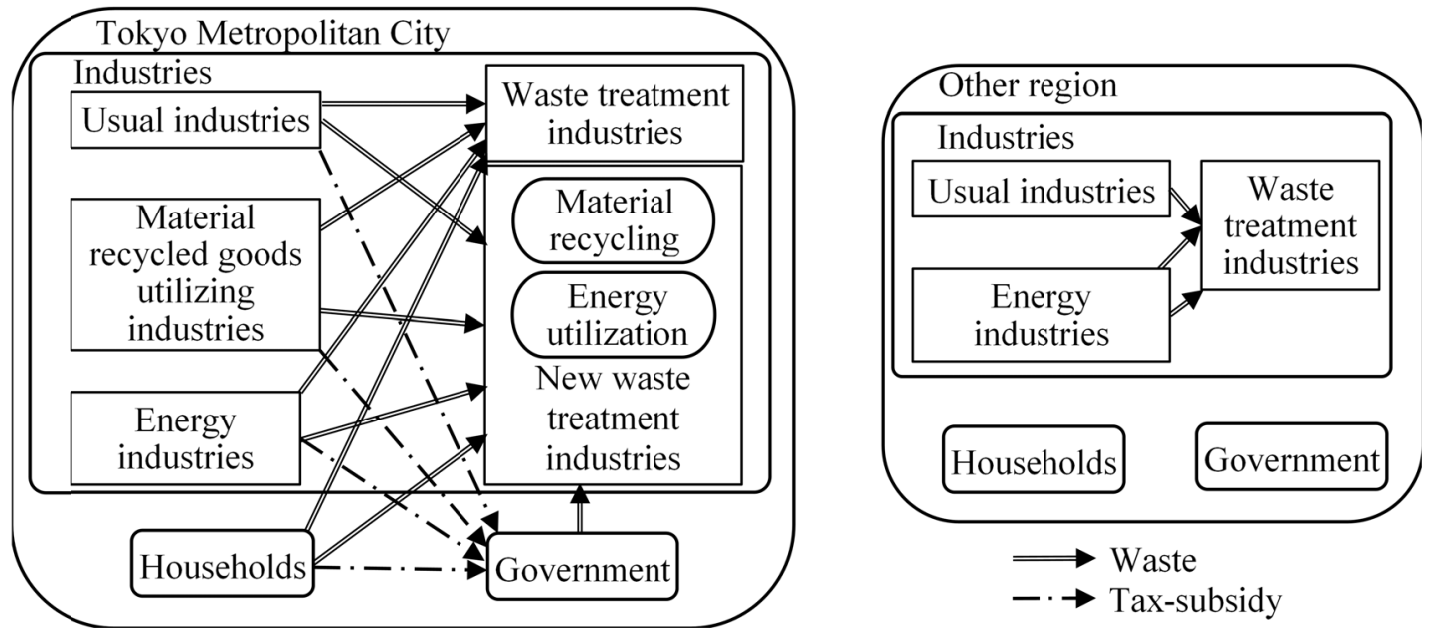

Figure 4. Flow chart of waste and tax-subsidy

We conduct this simulation with linear programming software LINGO of the LINDO Systems Inc.

Only essential model equations are presented in this paper as the model which we constructed in the study is composed of 88 equations and all of them cannot be included.

\subsection{Material Balance of Usual Goods}

The left side represents supply of goods, and the right side represents demand for goods. This equation describes demand-supply balance for each goods. Every usual goods industry supply more than their total demand.

$$
\begin{gathered}
X_{i} \geq A_{i 1} X_{1}+A_{i 2} X_{2}+A_{i 3} X_{3}+A_{i 4} X_{4}+A_{i 5} X_{5}+A_{i 6} X_{6}+A_{i 7} X_{7}+A_{i 8} X_{8}+A_{i 9} X_{9} \\
+C_{i}^{T}+G_{i}^{T}+I_{i}^{T}+E_{i}^{T}-M_{i}^{T}+C_{i}^{R}+G_{i}^{R}+I_{i}^{R}+E_{i}^{R}-M_{i}^{R}
\end{gathered}
$$

where

subscript $i=1,7 \quad j=1,2,3,4,5,6,7,8,9$

1: Usual industries in Tokyo, 2: Energy industries in Tokyo, 3: Waste treatment industries in Tokyo, 4: New waste treatment industries in Tokyo (material recycling), 5: New waste treatment industries in Tokyo (energy utilization), 6: Material recycled goods utilizing industries in Tokyo, 7: Usual industries in other region, 8: Energy industries in other region, 9: Waste treatment industries in other region, g: Government

superscript T: Tokyo metropolitan city, R: Other region

$X_{j}$ : Endogenous column vectors of production of each industry in sector $j$

$A_{i j}$ : Exogenous matrices of input coefficients of goods $i$ to each industry in sector $j$

$C_{i}$ : Endogenous column vectors of households' consumption of goods $i$

$G_{i}$ : Endogenous column vectors of government's consumption of goods $i$

$I_{i}$ : Endogenous column vectors of gross investment demand of goods $i$

$E_{i}$ : Endogenous column vectors of export of goods $i$

$M_{i}$ : Endogenous column vectors of import of goods $i$

\subsection{Balance of Material Recycled Goods Flow}

The first entity of left side represents supply of goods which have treated at New waste treatment industries in Tokyo (material recycling). The right side represents demand for goods.

$$
\begin{gathered}
X_{4}+X_{6} \geq A_{61} X_{1}+A_{62} X_{2}+A_{63} X_{3}+A_{64} X_{4}+A_{65} X_{5}+A_{66} X_{6}+A_{67} X_{7}+A_{68} X_{8}+A_{69} X_{9} \\
+C_{6}^{T}+G_{6}^{T}+I_{6}^{T}+E_{6}^{T}-M_{6}^{T}+C_{6}^{R}+G_{6}^{R}+I_{6}^{R}+E_{6}^{R}-M_{6}^{R}
\end{gathered}
$$

\subsection{Balance of Energy Flow}

\subsubsection{Total Energy Demand}

$$
C E_{j}=\widetilde{X}_{j} \theta_{j}
$$




$$
C C_{e}=C_{e} \gamma
$$

where

$C E_{j}$ : Endogenous column vectors of energy demand amount of $j$ industries

$\theta_{j}$ : Exogenous column vectors of energy demand coefficients of $j$ industries

$C C_{e}$ : Endogenous values of total energy demand of households

$C_{e}$ : Endogenous values of households' consumption of each energy

$\gamma$ : An exogenous value of energy demand coefficients of households

$\widetilde{X}_{j}$ : Diagonal matrices whose diagonal elements are the elements of $X_{j}$

subscript $e=2,8$

\subsubsection{Demand of Each Energy}

This equation holds for both 'Tokyo metropolitan city' and 'Other region'.

$$
\begin{gathered}
C E_{j}=\sum C O_{e j}+\sum P R_{e j}+\sum N G_{e j}+\sum G L_{e j}+\sum K S_{e j}+\sum D O_{e j}+\sum O P_{e j}+\sum C P_{e j}+\sum C M P_{e j} \\
+\sum A P_{e j}+\sum U G_{e j}+\sum R H S_{e j} \\
C C_{e}=P_{e}(1) C O_{e c}+P_{e}(2) P R_{e c}+P_{e}(3) N G_{e c}+P_{e}(4) G L_{e c}+P_{e}(5) K S_{e c}+P_{e}(6) D O_{e c}+P_{e}(7) O P_{e c} \\
\quad+P_{e}(8) C P_{e c}+P_{e}(9) C M P_{e c}+P_{e}(10) A P_{e c}+P_{e}(11) U G_{e c}+P_{e}(12) R H S_{e c}
\end{gathered}
$$

where

$C O_{2 j}, P R_{2 j}, N G_{2 j}, G L_{2 j}, K S_{2 j}, D O_{2 j}, O P_{2 j}, C P_{2 j}, C M P_{2 j}, A P_{2 j}, U G_{2 j}, R H S_{2 j}, C O_{8 j}, P R_{8 j}, N G_{8 j}, G L_{8 j}$, $K S_{8 j}, D O_{8 j}, O P_{8 j}, C P_{8 j}, C M P_{8 j}, A P_{8 j}, U G_{8 j}, R H S_{8 j}$

: Endogenous column vectors of energy demand for each energy by each industry in sector $j$
CO: Coal mining,
$P R$ : Crude petroleum,
$N G$ : Natural gas,
GL: Gasoline,
$K S$ : Kerosene, $D O$ : Diesel oil, $O P$ : Miscellaneous petroleum refinery products,
$C P$ : Coal products,
CMP: Electricity,
$A P$ : Private power generation,
$U G$ : Gas supply,

$R H S$ : Steam and hot water supply

$C O_{e c}, P R_{e c}, N G_{e c}, G L_{e c}, K S_{e c}, D O_{e c}, O P_{e c}, C P_{e c}, C M P_{e c}, A P_{e c}, U G_{e c}, R H S_{e c}$

: Endogenous values of energy demand for each energy by households

subscript $c$ : Households

\subsubsection{Total Energy Supply}

Equation (7) represents that coal mining sector supply more than their total demand. Similar equations hold for each energy. For energy in 'Other region', left sides are all singular.

$$
k_{2}(1) X_{2}(1)+k_{5}(1) X_{5}(1) \geq \sum l C O_{2 j}+C O_{2 c}^{T}+C O_{2 c}^{R}
$$

where

$k_{i}$ : Exogenous row vectors of energy supply coefficient of $i$ industries

$l$ : A row vector for summation

\subsection{Balance of Waste Flow}

The total waste discharged amount consists of discharged waste by production of each industry and by household consumption. Similar equation holds for 'Other region'.

$$
W^{T}=A_{w 1} X_{1}+A_{w 2} X_{2}+A_{w 5} X_{5}+A_{w 6} X_{6}+\left(l C_{1}^{T}+l C_{2}^{T}+l C_{6}^{T}+l C_{7}^{T}+l C_{8}^{T}\right) A_{w c}
$$

where

subscript $w$ : Waste

$W$ : Endogenous column vectors of total disposal amount of waste

\subsection{Amount of Emission of $G H G$}

The amount of GHG emitted is calculated by multiplying GHG emission coefficient to products of each industry 
and household's consumption amount respectively.

$$
G H G^{T}=A_{z 1} X_{1}+A_{z 2} X_{2}+A_{z 3} X_{3}+A_{z 4} X_{4}+A_{z 5} X_{5}+A_{z 6} X_{6}+A_{z c}\left(C_{2}^{T}+C_{8}^{T}\right)
$$

where

subscript $z$ : Greenhouse gas

$G H G$ : An endogenous variable of total emission of GHG

\subsection{Value Balances}

\subsubsection{Value Balances of Usual Industries}

The left side represents income due to selling goods, and the right side represents expenditure needed for production. As we assume perfect competitive market, income should not exceed expenditure because firms produce until there is no excess profit. The last entity in right side represents waste discharging tax imposed on industries in Tokyo by multiplying the amount of waste discharged by production of goods and waste discharging tax rate.

$$
\begin{aligned}
P_{1} \widetilde{X_{1}} \leq & P_{1} A_{11} \widetilde{X_{1}}+P C E_{21}+P_{3} A_{31} \widetilde{X_{1}}+P_{6} A_{61} \widetilde{X_{1}}+P_{7} A_{71} \widetilde{X_{1}}+P C E_{81}+P_{9} A_{91} \widetilde{X_{1}}+v_{1} \widetilde{X_{1}}+\delta_{1} \widetilde{X_{1}} \\
& +\tau_{1} \widetilde{P_{1}} \widetilde{X_{1}}+\tau_{w}{ }^{\mathrm{t}} X_{1} A_{w 1}
\end{aligned}
$$

where

$v_{j}$ : Exogenous row vectors of households' income of each industry in $j$ industries

$\delta_{j}$ : Exogenous row vectors of depreciation of each industry in $j$ industries

$\tau_{j}$ : Exogenous row vectors of indirect tax of each industry in $j$ industries

$\tau_{w}$ : An exogenous value of tax rate on discharging waste, operating variable

Similar equations hold for 'Material recycled goods utilizing industries in Tokyo', 'Usual industries in other region', energy industries and waste treatment industries.

Expenditure on energy needed for production is equivalent to purchase of demanded amount which is determined by balance of energy mentioned above. Hence, instead of input-output coefficient, equation (11) is used for expenditure on energy which is in right side of value balance of each industry.

$$
\begin{aligned}
P C E_{e j} & =P_{e}(1)^{\mathrm{t}} C O_{e j}+P_{e}(2)^{\mathrm{t}} P R_{e j}+P_{e}(3)^{\mathrm{t}} N G_{e j}+P_{e}(4)^{\mathrm{t}} G L_{e j}+P_{e}(5)^{\mathrm{t}} K S_{e j}+P_{e}(6)^{\mathrm{t}} D O_{e j} \\
& +P_{e}(7)^{\mathrm{t}} O P_{e j}+P_{e}(8)^{\mathrm{t}} C P_{e j}+P_{e}(9)^{\mathrm{t}} C M P_{e j}+P_{e}(10)^{\mathrm{t}} A P_{e j}+P_{e}(11)^{\mathrm{t}} T G_{e j}+P_{e}(12)^{\mathrm{t}} R H S_{e j}
\end{aligned}
$$

where

$P C E_{e j}$ : Endogenous row vectors of expenses for energy required for production of $j$ industries

$P_{e}$ : Endogenous row vectors of price rates of goods $i$

2.6.2 Value Balances of New Waste Treatment Industries in Tokyo (material recycling)

The last entity in left side represents subsidy for introducing new waste treatment industries and extending their activities. The subsidy comes from waste discharging tax which is the last entity of equation (10). Similar equation holds for 'New Waste Treatment Industries in Tokyo (energy utilization)'.

$$
P_{4} \widetilde{X_{4}}+\tau_{4}^{s}=P_{1} A_{14} \widetilde{X_{4}}+P C E_{24}+P_{6} A_{64} \widetilde{X_{4}}+P_{7} A_{74} \widetilde{X_{4}}+P C E_{84}+v_{4} \widetilde{X_{4}}+\delta_{4} \widetilde{X_{4}}+\tau_{4} \widetilde{P_{4}} \widetilde{X_{4}}
$$

where

$\tau_{j}^{s}$ : Endogenous row vectors of subsidy for industries

\subsection{Disposal Income}

Disposal income of household is given by national income minus direct tax. Similar equation holds for 'Other region'.

$$
Y_{d}^{T}=\left(1-\tau^{d}\right)\left(v_{1} X_{1}+v_{2} X_{2}+v_{3} X_{3}+v_{4} X_{4}+v_{5} X_{5}+v_{6} X_{6}\right)
$$

where

$Y_{d}$ : Endogenous values of disposal income of households

$\tau^{d}$ : An exogenous value of direct tax rate

\subsection{Consumption and Saving of Households}

Disposal income $Y_{d}$ is divided into consumption and savings of every goods by certain proportion. The sum of 
proportion of consumption and saving is 1 . Similar equations hold for 'Other region'.

$$
\begin{gathered}
P_{i} \widetilde{C_{l}^{T}}+\tau_{w}{ }^{\mathrm{t}} A_{w c} \widetilde{C_{l}^{T}}=Y_{d}^{T} \alpha_{i}^{T} \\
S^{p T}=\beta^{T} Y_{d}^{T} \\
l \alpha_{i}^{T}+\beta^{T}=1
\end{gathered}
$$

where

$\alpha_{i}$ : Exogenous row vectors of consumption ratio with goods i of households

$\beta$ : Exogenous values of saving ratio of households

$S^{p}$ : Endogenous values of saving of households

\subsection{Objective Function}

We set GRP as objective function and maximized it under constraints of 87 equations.

$$
\begin{gathered}
G R P=v_{1} X_{1}+v_{2} X_{2}+v_{3} X_{3}+v_{4} X_{4}+v_{5} X_{5}+v_{6} X_{6}+\delta_{1} X_{1}+\delta_{2} X_{2}+\delta_{3} X_{3}+\delta_{4} X_{4}+\delta_{5} X_{5} \\
+\delta_{6} X_{6}+\tau_{1} \widetilde{P_{1}} X_{1}+\tau_{2} \widetilde{P_{2}} X_{2}+\tau_{3} \widetilde{P_{3}} X_{3}+\tau_{4} \widetilde{P}_{4} X_{4}+\tau_{5} \widetilde{P_{5}} X_{5}+\tau_{6} \widetilde{P_{6}} X_{6} \\
\max G R P
\end{gathered}
$$

\subsection{Case Setting}

We set three cases as shown in Table 2. Case 0 is the baseline case. In case1, new waste treatment industries are introduced but there is no tax-subsidy policy. In case2, waste discharging tax is implemented. The tax is a specific duty which is imposed on discharged amount of waste. All the money collected by the tax is spent as subsidy to Waste treatment industries in Tokyo and New waste treatment industries in Tokyo.

Table 2. Case setting

\begin{tabular}{lcc}
\hline & New industries & Tax-subsidy \\
\hline case 0 & $\times$ & $\times$ \\
case 1 & $\checkmark$ & $\times$ \\
case2 & $\checkmark$ & $\checkmark$ \\
\hline
\end{tabular}

In the next chapter, with GHG emissions restriction at the 2011 level in case 0 is referred to as case $0(0 \%)$, and we analyze the results with case $0(0 \%)$ as the standard.

\section{Simulation Results}

\subsection{Effect of Introducing New Industries}

Figure 5 shows changes in GRP and Gross Domestic Product (GDP) along with GHG emissions restriction. In case $0(0 \%)$ which is baseline case and GHG emissions amount is 2011 level, GRP is 99008680 million yen and GDP is 553089100 million yen while the actual value in 2011 is 100868188 million yen for GRP and 548754 636 million yen for GDP. Differences between value of simulation result and actual value for GRP and GDP are $1.84 \%$ and $0.79 \%$, respectively. Therefore, we consider that the simulation model used in the research and the results are valid. In case0, we got result only with restriction on GHG emissions till $-6 \%$ of that of 2011 . Meanwhile we got till $-14.5 \%$ for case 1 which is case with new industries. In both cases, GRP and GDP fell down as we tighten up GHG emissions restriction. However in case1, economic level was kept higher than case0 $(0 \%)$ till $-8 \%$ GHG emissions restriction. These indicate that deterioration in economic scale was suppressed by introduction of new industries. Here $-8 \%$ GHG emissions restriction equals to only $3.5 \%$ GHG emissions reduction from 2000 level, which cannot fulfill the GHG reduction target of $-25 \%$ from 2000 level. 


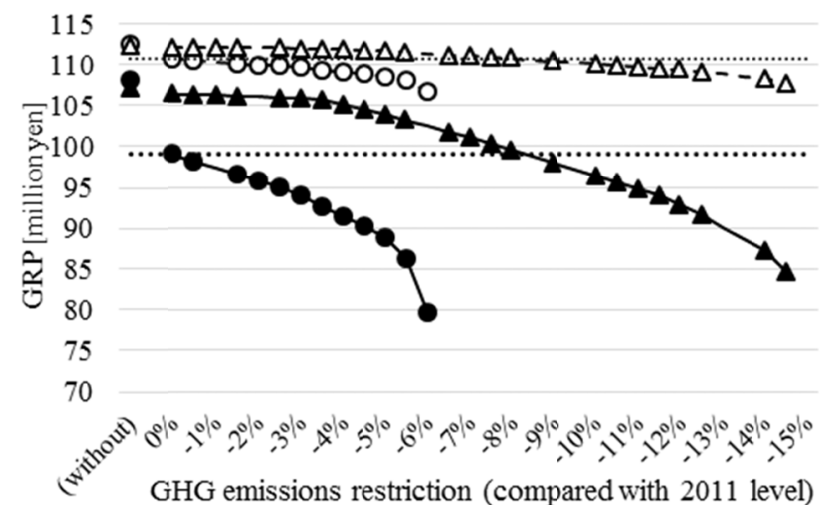

575

550

525

$500 \stackrel{\mathrm{D}}{\longrightarrow} \longrightarrow$ case $0 \mathrm{GRP}$

$475 \stackrel{5}{\cong} \longrightarrow$ case1 GRP

450 豆......... case0 (0\%) GRP

425

400

375

350

- - - case0 GDP

- $-\boldsymbol{\Delta}$ - case1 GDP

case $0(0 \%)$ GDP

GHG emissions restriction (compared with 2011 level)

Figure 5. Change in GRP and GDP along with GHG emissions restriction

Figure 6 shows final disposal amount when there is no restriction and with $0 \%$ restriction in case 0 and case 1 . Numbers shown in the figure is ratio of all the cases to case $0(0 \%)$. Compared with case $0(0 \%)$, final disposal amount was reduced by $4.2 \%$ with introduction of new industries.

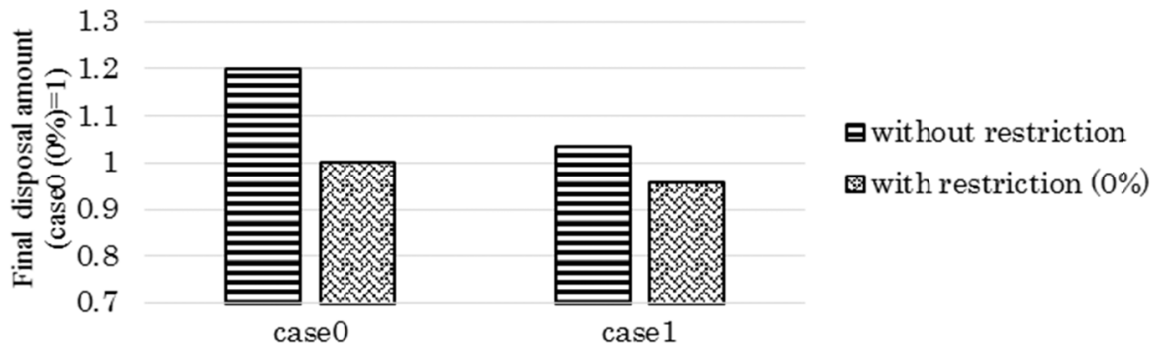

Figure 6. Final disposal amount with case 0 and case 1

\subsection{Effect of Introducing Tax and Subsidy}

Figure 7 shows results of case2. In case2, we were unable to get results when tax rate is more than $70 \mathrm{yen} / \mathrm{kg}$. We got results of tax rate of 1 yen $/ \mathrm{kg}, 10$ yen $/ \mathrm{kg}, 30 \mathrm{yen} / \mathrm{kg}, 50 \mathrm{yen} / \mathrm{kg}$ and $70 \mathrm{yen} / \mathrm{kg}$. Numbers in vertical axis represent ratio of final disposal amount per GRP to case $0(0 \%)$. With tax rate of $10 \mathrm{yen} / \mathrm{kg}$ and $50 \mathrm{yen} / \mathrm{kg}$, the numbers were kept less than 0.9 from $0 \%$ GHG emissions restriction.

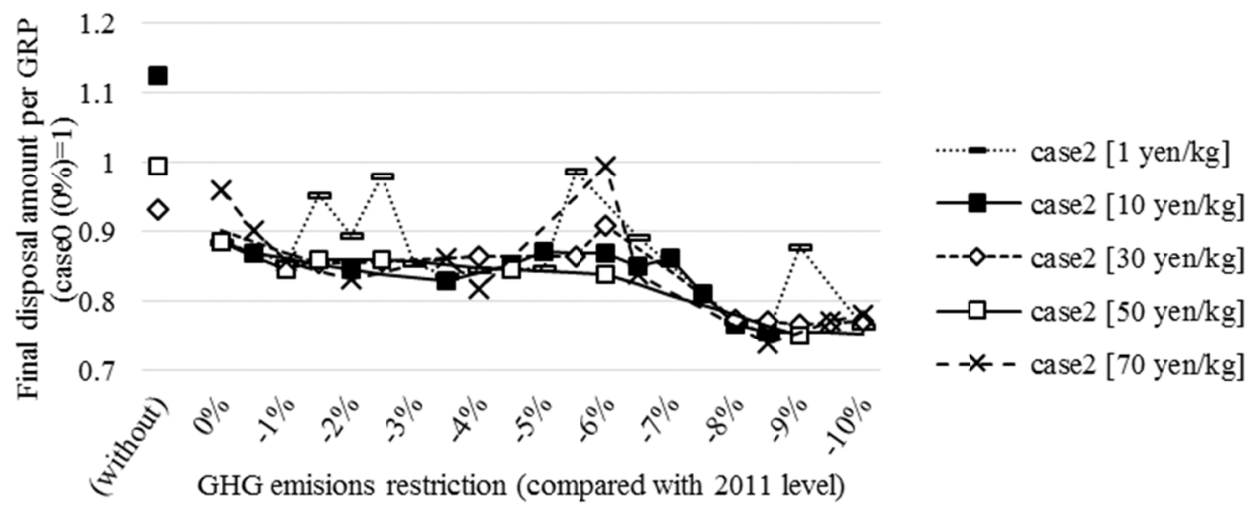

Figure 7. Change in final disposal amount per GRP with case2

Results of case 2 [10 yen $/ \mathrm{kg}]$ and case 2 [50 yen/ $/ \mathrm{kg}$ ] show that final disposal amount reduced by $5 \%$ and final disposal amount per GRP reduced by around $11 \%$ (see Table 3 ). The values rose when there is $-6 \%$ or $-8 \%$ GHG emissions restriction. In Tokyo, depending on region and types of waste, waste discharging tax is set to at most $50 \mathrm{yen} / \mathrm{kg}$. Taking into account both the effects and social acceptancy, $10 \mathrm{yen} / \mathrm{kg}$ was optimal tax rate. 
Table 3. Values of case 2 compared with case $0(0 \%)$

\begin{tabular}{cccccccc}
\hline & \multicolumn{3}{c}{ case0 } & \multicolumn{3}{c}{ case2 [10 yen/kg] } & \multicolumn{3}{c}{ case2 [50 yen/kg] } \\
\cline { 2 - 8 } & $(0 \%)$ & $(0 \%)$ & $(6 \%)$ & $(8 \%)$ & $(0 \%)$ & $(6 \%)$ & $(8 \%)$ \\
\hline Final disposal amount & 1 & 0.9504 & 0.8987 & 0.7711 & 0.9504 & 0.8678 & - \\
Final disposal amount per GRP & 1 & 0.8861 & 0.8677 & 0.7670 & 0.8845 & 0.8379 & - \\
\hline
\end{tabular}

Production of each industry of case 2 [10 yen/kg] (8\%) had not much difference among case $0(0 \%)$ and case 1 (8\%) (see Figure 8 ). On the other hand, households' consumption in case2 [10 yen $/ \mathrm{kg}](8 \%)$ fell down by $7.2 \%$ and $7.0 \%$ compared with case $0(0 \%)$ and case $1(8 \%)$ respectively. These results revealed that introduction of waste discharging tax and subsidy had more effects on households than on industries.

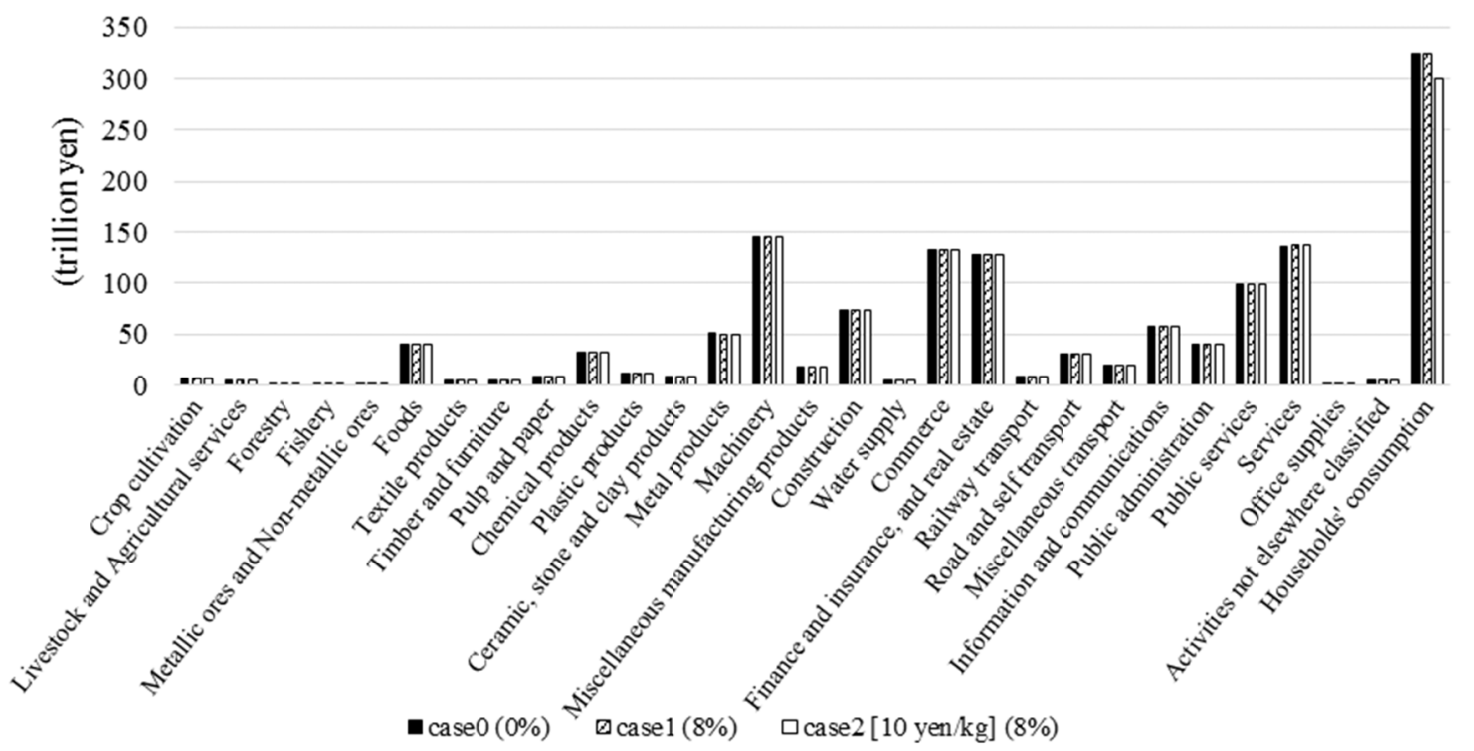

Figure 8. Production of each industry and consumption

\section{Conclusions}

In this study, we clarified the effects of thorough waste recycling on economy and environment. We selected Tokyo Metropolitan City as the study area. Focusing on utilization of waste, we conducted an interregional input-output model which takes into account economic activities of not only Tokyo Metropolitan City but also other region. The model includes economic activity structure, balance of waste flow, amount of GHG and balance of energy flow. With restriction on GHG emissions amount, we conducted computer simulation. The results show that promotion of waste recycling contributed with keeping economic level above the baseline till $-3.5 \%$ GHG emissions reduction from 2000 level. When we implemented tax-subsidy policy with tax rate of 10 yen $/ \mathrm{kg}$, both final disposal amount and final disposal amount per GRP were kept lower than the baseline case. However, only promoting waste recycling was not enough to improve the environment. The GHG reduction target, which is $-25 \%$ from 2000 level, was unable to be achieved only through promotion of waste recycling. We also have to promote other environmental countermeasures to meet the target.

Therefore our future work includes other types of renewable energy such as solar power and wind power in order to achieve the target set by Tokyo Metropolitan Government. Moreover, when we utilize biomass, not only GHG emissions but also water pollutants can be reduced. Besides while thinking of utilizing waste, it is important to consider the size and allocation of treatment facility because there is a trade-off relation between transportation cost and environmental pollution. We will further conduct comprehensive evaluation with equations for transportation network problem to the model and using different indexes such as water pollution and air pollution.

\section{References}

Bioenergy. (2014, February 19). Effect to Environment. Retrieved from http://www.bio-energy.co.jp/effect/index.php 
Bureau of environment, Tokyo Metropolitan Government. (2007). Tokyo Climate Change Strategy -A Basic Policy for the 10-Year Project for a Carbon-Minus Tokyo -. Retrieved March 26, 2014 from https://www.kankyo.metro.tokyo.jp/climate/attachement/tokyo-climate-change-strategy_2007.6.1.pdf

Bureau of environment, Tokyo Metropolitan Government. (2012). Survey on use of renewable energy in Tokyo. $\begin{array}{llll}\text { Retrieved July } & 24, & 2013 & \text { from }\end{array}$ https://www.kankyo.metro.tokyo.jp/energy/renewable_energy/attachement/tyousa_201203.pdf

Bureau of environment, Tokyo Metropolitan Government. (2013). 3Rs in Tokyo. Retrieved July 23, 2014 from https://www.kankyo.metro.tokyo.jp/resource/attachement/3RsInTOKYO2013.pdf

Bureau of environment, Tokyo Metropolitan Government. (2013). Final Energy Consumption and Greenhouse Gas Emissions in Tokyo (preliminary figures for FY2013). Retrieved February 19, 2014 from http://www.kankyo.metro.tokyo.jp/climate/other/attachement/2013sokuho.pdf

Bureau of General Affairs, Tokyo Metropolitan Government. (2010). 2005 Input-Output tables for Tokyo

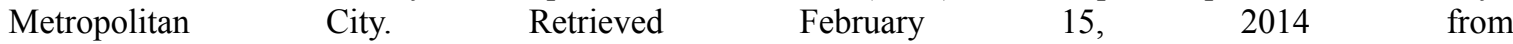
http://www.toukei.metro.tokyo.jp/sanren/2005/sr05t1.htm

Chang, Y. F., \& Lin, S. J. (1998). Structural decomposition of industrial $\mathrm{CO}_{2}$ Emission in Taiwan: an input-output approach. Energy Policy, 26(1), 5-12. https://doi.org/10.1016/S0301-4215(97)00089-X

Council for Promotion of Biomass Utilization. (2012). Current situation and issue related to biomass. Retrieved August 5, 2013 from http://www.maff.go.jp/j/biomass/b_kenntou/01/pdf/1_1.pdf

Higano, Y. (1996). Distribution of the Value added to the Input of the Environmental Goods based on Material Balance Principle. Studies in Regional Science, 26(1), 181-187. https://doi.org/10.2457/srs.26.181

Iwata, T., \& Shimada, S. (2008). Model Development for Evaluating Countermeasures Effects against Livestock Manure Management (Study on Reasonable Budget Planning for Effective Utilization of Livestock Manure). Journal of the Japan Institute of Energy, 87(9), 719-730. https://doi.org/10.3775/jie.87.719

Japan Institute of Wastewater Engineering and Technology. Biofuel and power generation from sewage sludge. Retrieved June 8, 2014 from http://www.jiwet.or.jp/quarterly/n003/pdf/n003-010.pdf

Li, Y., Zou, S., Xu, F., Yabar, H., \& Higano, Y. (2012). The Impact of Introducing Recycling Taxes on China's Environmental Policy: Case Study on E-waste Recycling. Journal of Sustainable Development, 5(4), 83-98. https://doi.org/10.5539/jsd.v5n4p83

Ministry of Agriculture, Forestry, and Fishery. Statistical Survey on Food Waste. Retrieved March 19, 2014 from http://www.e-stat.go.jp/SG1/estat/List.do?lid=000001102810

Ministry of Environment. (2012). Report on survey for waste transfer measures and waste circular utilization amount FY2011. Retrieved March 19, 2014 from http://www.env.go.jp/recycle/report/h24-01/

Ministry of Environment. Survey on condition of general waste disposal FY2011. Retrieved May 3, 2014 from http://www.env.go.jp/recycle/waste_tech/ippan/h23/index.html

Ministry of International Affairs and Communications. 2012 Economic Census for Business Activity. Retrieved August 3, 2014 from http://www.e-stat.go.jp/SG1/estat/NewList.do?tid=000001056219

Ministry of International Affairs and Communications. 2013 Statistics on Livestock. Retrieved March 19, 2014 from http://www.e-stat.go.jp/SG1/estat/List.do?lid=000001115087

Mitshashi, K., \& Higano, Y. (2005). Research in Energy Utilization of Waste in Tokyo, Collected Papers for Presentation in the $42^{\text {nd }}$ Annual Meeting of the Japan Section of the RSAI, 127-132 (in Japanese).

Someyashoten group. VDF process. Retrieved February 19, 2014 from http://www.vdf.co.jp/vdf_file.html

Tsuiki, M., \& Harada, Y. (1997). Livestock excretion and future theme in Japan, Environmental Conservation and New Animal Industry, 15-29.

Uchida, S., \& Higano, Y. (2006). An Evaluation of the Policy Promoting Energy Recovery from Wastes. Studies in Regional Science, 30(1), 21-35. https://doi.org/10.2457/srs.36.21

\section{Copyrights}

Copyright for this article is retained by the author(s), with first publication rights granted to the journal.

This is an open-access article distributed under the terms and conditions of the Creative Commons Attribution license (http://creativecommons.org/licenses/by/4.0/). 